\title{
Cell proliferation in the post-surgical stomach, dietary salt, and the effect of $H$ pylori eradication
}

\author{
P Willis, D A F Lynch, R Prescott, S Lamonby
}

\begin{abstract}
Aims-To study the epithelial kinetics of the post-surgical stomach with reference to dietary salt intake and $\boldsymbol{H}$ pylori.

Methods-Endoscopic biopsies of the antrum/anastomosis and corpus were taken for histology and MIB-1 immunostaining. The labelling index (LI\%) was determined in the three zones of the gastric glands (zone $1=$ surface + gastric pit; zone 2 = isthmus; zone $3=$ gland base) in patients with vagotomy and pyloroplasty $(n=12)$, gastroenterostomy + vagotomy $(n=4)$, partial gastrectomy $(\mathbf{n}=3)$, and Billroth I operation $(\mathbf{n}=3)$. Dietary salt was determined by urinary sodium/creatinine ratio. Twelve patients were $H$ pylori positive (10 vagotomy and pyloroplasty; 2 partial gastrectomy) and had a repeat biopsy three months after antihelicobacter treatment $(10$ were $H$ pylori negative after treatment).

Results-There was no correlation between salt intake and antrum/anastomosis $(r=-0.34 ; p=0.2)$ or corpus $(r=-0.16$; $\mathbf{p}=0.2)$ labelling indices. Gastric mucosal proliferation is increased in the antrum/ anastomosis compared to the corpus in $H$ pylori positive $(\mathrm{p}=0.014)$ but not $H$ pylori negative subjects $(p=0.084)$. This may reflect the different types of post-surgical stomach in each group. Gastric mucosal proliferation is reduced in antrum/anastomosis $(p=0.002)$ and corpus $(\mathrm{p}=0.016)$ following $\mathrm{H}$ pylori eradication.

Conclusions-Dietary salt does not influence gastric mucosal proliferation in the post-surgical stomach but $H$ pylori may have a role in gastric stump carcinogenesis. (F Clin Pathol 1999;52:665-669)
\end{abstract}

Keywords: epithelial kinetics; post-surgical stomach; H pylori

Department of Histopathology, Blackburn Royal Infirmary, Blackburn BB2 3LR, UK $\mathrm{P}$ Willis

R Prescott

S Lamonby

Department of Gastroenterology, Blackburn Royal Infirmary

D A F Lynch

Correspondence to: Dr Lynch.

Accepted for publication 14 May 1999

The post-surgical stomach is at increased risk of cancer. ${ }^{1-4}$ Bile reflux, which is an invariable consequence of operations that remove or bypass the pylorus, ${ }^{56}$ is thought to be a major factor in carcinogenesis. Bile and Helicobacter pylori have a synergistic effect on the development of intestinal metaplasia in the gastric mucosa, ${ }^{7}$ an important step in the development of gastric cancer,.

Dietary salt intake ${ }^{8}$ and $H$ pylori infection ${ }^{9-12}$ are risk factors for the development of gastric cancer in the intact stomach. Epithelial hyperproliferation is important in gastric carcinogenesis. ${ }^{13}$ Gastric epithelial proliferation is increased in $H$ pylori gastritis, and eradi- cation of the organism returns epithelial proliferation to normal levels in the intact stomach. ${ }^{14-18}$ Dietary salt has been shown to correlate with gastric epithelial proliferation in the intact stomach. ${ }^{19}$

Recent work on gastric epithelial kinetics in the post-surgical stomach suggests that $H p y$ lori and bile also have a synergistic effect on mucosal proliferation in the gastric remnant, in that gastric mucosal proliferation is increased in the post-surgical stomach compared with the intact stomach, and $H$ pylori infection of the gastric remnant is associated with greater mucosal proliferation than when this organism is absent. ${ }^{20}$

Our aims in this investigation were to study further the epithelial kinetics of the postsurgical stomach with reference to $H$ pylori and dietary salt intake.

\section{Methods}

Patients undergoing routine diagnostic endoscopy were recruited with their informed consent. Those taking histamine receptor antagonists, proton pump inhibitors, nonsteroidal anti-inflammatory drugs, antibiotics, or bismuth salts were excluded. The study was approved by the hospital ethics committee.

Twenty two patients were recruited (table 1) (16 men and six women; median age 61 years, range 40 to 74 ). None had previously undergone biliary tract surgery. Twelve subjects had undergone vagotomy and pyloroplasty, four gastroenterostomy and vagotomy, three Polya gastrectomy, and three Billroth I partial gastrectomy.

\section{URINARY Na/CREATININE}

Dietary salt was measured by determining the urinary sodium to creatinine ratio. ${ }^{21} \mathrm{~A}$ sample of urine, passed between 8 am and midday, was collected in a universal container. Urinary sodium and creatinine concentrations were measured using a Vitros analyser (Johnson and Johnson Clinical Diagnostics Inc).
ENDOSCOPIC BIOPSIES

At endoscopy, biopsies were taken from within $5 \mathrm{~cm}$ of the anastomosis (4) or the antrum (4), and from the corpus (4), using standard forceps. Biopsies from each site were placed in $10 \%$ formalin, routinely processed, and stained with haematoxylin and eosin. All endoscopies were performed by one endoscopist.

\section{H PYLORI}

A modified Giemsa stain was used to detect $H$ pylori in the antrum/anastomosis and corpus biopsies. All sections were examined by one 
Table 1 The age, sex, urinary sodium ( $\mathrm{Na}$ ) to creatinine (Creat) ratio, type of gastric surgery, and H pylori status of the patients studied

\begin{tabular}{|c|c|c|c|c|c|}
\hline Patient & $\begin{array}{l}\text { Age } \\
\text { (years) }\end{array}$ & Sex & $\begin{array}{l}\text { Urinary } \\
\text { Na:Creat }\end{array}$ & Surgery & H pylori \\
\hline 1 & 51 & $M$ & 0.04 & PG & POS \\
\hline 2 & 59 & $M$ & 0.05 & $\mathrm{~V}+\mathrm{P}$ & POS \\
\hline 3 & 41 & M & 0.03 & $\mathrm{~V}+\mathrm{P}$ & POS \\
\hline 4 & 61 & $M$ & - & $\mathrm{V}+\mathrm{P}$ & POS \\
\hline 5 & 53 & M & 0.03 & $\mathrm{~V}+\mathrm{P}$ & POS \\
\hline 6 & 66 & $\mathrm{~F}$ & 0.03 & $\mathrm{~V}+\mathrm{P}$ & POS \\
\hline 7 & 49 & M & 0.04 & $\mathrm{~V}+\mathrm{P}$ & POS \\
\hline 8 & 67 & $\mathrm{M}$ & 0.01 & $\mathrm{~V}+\mathrm{P}$ & POS \\
\hline 9 & 65 & $\mathrm{~F}$ & 0.04 & $\mathrm{~V}+\mathrm{P}$ & POS \\
\hline 10 & 61 & $\mathrm{M}$ & 0.02 & $\mathrm{~V}+\mathrm{P}$ & POS \\
\hline 11 & 69 & M & - & PG & POS \\
\hline 12 & 48 & $\mathrm{~F}$ & 0.01 & $\mathrm{~V}+\mathrm{P}$ & POS \\
\hline 13 & 71 & $\mathrm{~F}$ & - & PG & NEG \\
\hline 14 & 61 & $\mathrm{~F}$ & 0.04 & GE & NEG \\
\hline 15 & 68 & M & 0.02 & B-I & NEG \\
\hline 16 & 69 & $\mathrm{M}$ & 0.03 & B-I & NEG \\
\hline 17 & 74 & $M$ & - & GE & NEG \\
\hline 18 & 54 & M & 0.07 & $\mathrm{~V}+\mathrm{P}$ & NEG \\
\hline 19 & 64 & M & - & $\mathrm{V}+\mathrm{P}$ & NEG \\
\hline 20 & 47 & M & 0.02 & GE & NEG \\
\hline 21 & 71 & M & 0.05 & GE & NEG \\
\hline 22 & 47 & $\mathrm{M}$ & 0.08 & B-I & NEG \\
\hline
\end{tabular}

B-I, Billroth I operation; GE, vagotomy and gastroenterostomy; PG, Polya gastrectomy; V+P, vagotomy and pyloroplasty.

histopathologist with a special interest in gastrointestinal disease who was unaware of endoscopic diagnosis. Eradication of the microorganism was assumed to have occurred only if both antrum/anastomosis and corpus biopsies were negative.

MIB-1 IMMUNOSTAINING

Sections for immunohistochemical labelling with MIB-1 monoclonal antibody (1 in 100 dilution; Coulter Electronics) were placed in citrate buffer ( $\mathrm{pH}$ 6.0) and brought to boiling in a microwave oven at $650 \mathrm{~W}$. This procedure was repeated twice with five minute resting intervals between boiling. After cooling, the sections were labelled with MIB-1 using a three step avidin-biotin complex immunoperoxidase technique.

LABELLING INDEX

We counted only those sections with a full thickness of mucosa (epithelium to muscularis mucosae) and oriented perpendicularly to the epithelial surface. For the purpose of counting, the gastric mucosa was divided into three zones: zone 1 = surface and gastric pit; zone $2=$ isthmus; zone $3=$ gland base. The number of cells to be counted was determined by counting consecutive high power fields until the continuous mean varied by less than $5 \%$. The number of positively staining nuclei per 500 epithelial cell nuclei (or whole section when less than 500 cells were present) was counted in each zone and expressed as a percentage. This value corresponds to the labelling index (LI\%). Only unequivocally stained cells were counted as positive. All sections were counted by one person who was unaware of the endoscopic diagnosis and $H$ pylori status.

ERADICATION THERAPY

Antihelicobacter treatment consisted of a two week course of tetracycline $500 \mathrm{mg}$ four times daily, metronidazole $400 \mathrm{mg}$ three times daily,
Table 2 Details the total and zone 2 median (range) labelling indices (LI\%) in the antrum/anastomosis and corpus of the $H$ pylori positive (HP pos) and negative (HP neg) post-surgical stomachs

\begin{tabular}{lll}
\hline $\begin{array}{l}\text { Patient group/ } \\
\text { remnant site }\end{array}$ & HP pos (n=12) & HP neg $(n=10)$ \\
\hline $\begin{array}{l}\text { Antrum/anastomosis } \\
\text { Total LI\% }\end{array}$ & $33.6(13.7$ to 51.4$)$ & $31.1(12.7$ to 47.3$)$ \\
Zone 2 LI\% & $60.9(33.1$ to 83.4$)$ & $49.9(34.8$ to 8.4$)$ \\
& & \\
Corpus & & \\
Total LI\% & $17.7(3.4$ to 32.5$)$ & $20.7(9.6$ to 38.9$)$ \\
Zone 2 LI\% & $42.8(8.0$ to 65.8$)$ & $40.75(33.6$ to 56.8$)$ \\
\hline
\end{tabular}

and tripotassium dicitrato-bismuthate $120 \mathrm{mg}$ four times daily. Patients underwent repeat endoscopy and biopsy three months after completion of treatment.

STATISTICAL ANALYSIS

The Mann-Whitney U test was used for analysis of non-parametric data and Wilcoxon rank sum test was employed when analysing the preand post- $H$ pylori eradication data. Spearman rank analysis was used for the correlation studies. A probability ( $p$ ) value of less than 0.05 was regarded as significant.

\section{Results}

Twelve patients were positive for $H$ pylori (eight male and four female; median age 60 years, range 41 to 69 ). Ten subjects had vagotomy and pyloroplasty and two had a partial gastrectomy. Twelve of the antrum/anastomosis specimens and 10 of the corpus biopsy specimens were suitable for counting. In the $10 \mathrm{H}$ pylori negative subjects, all the antrum/anastomotic and corpus biopsies were suitable for counting.

CELL PROLIFERATION IN THE POST-SURGICAL STOMACH

Positive staining for MIB-1 varied in the same direction for all three zones. Most were situated in zone 2. For the purposes of this study total and zone $2 \mathrm{LI} \%$ are presented.

There was no difference in antrum/ anastomosis or corpus (total and zone 2) LI\% when comparing $H$ pylori positive patients with a post-surgical stomach to $H$ pylori negative subjects (table 2).

In $H$ pylori positive patients, antrum/ anastomosis total and zone $2 \mathrm{LI} \%$ were significantly increased compared with the corpus ( $\mathrm{p}=0.004$ and $\mathrm{p}=0.014$, respectively). Those subjects with an $H$ pylori negative postsurgical stomach had higher total $(p=0.01)$, but not zone $2(p=0.08), \mathrm{LI} \%$ in the antrum/ anastomosis compared with the corpus (table 2).

EFFECT OF H PYLORI ERADICATION

The effects of $H$ pylori eradication are shown in figs 1 and 2 and table 3 . The 12 patients who were positive for $H$ pylor $i$ were given antihelicobacter treatment and had further biopsies approximately three months later. Ten were negative for $H$ pylori following treatment. Of these, 10 biopsy specimens from antrum/ anastomosis and seven from the corpus were 

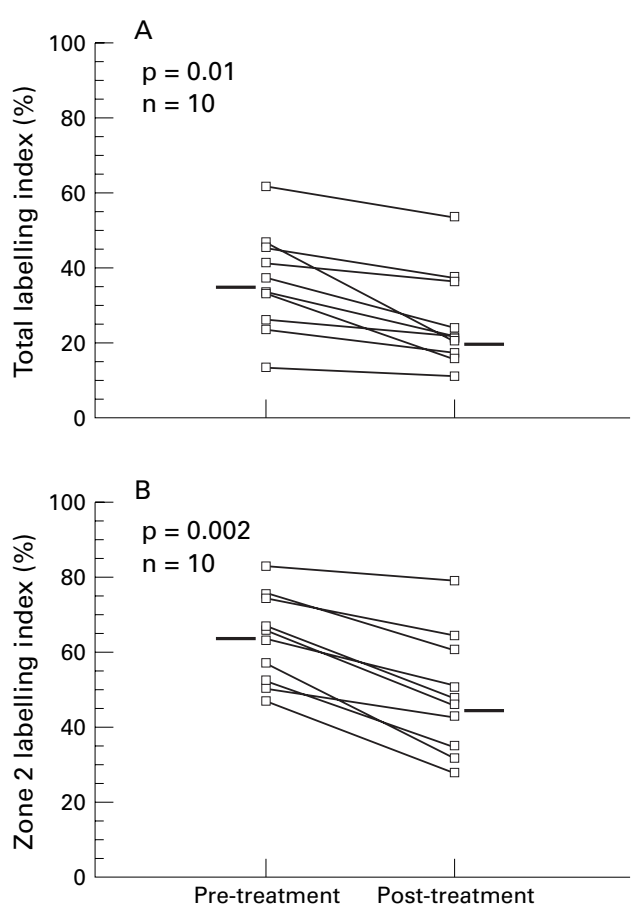

Figure 1 Total and zone 2 labelling indices in antrum before and after $H$ pylori eradication.
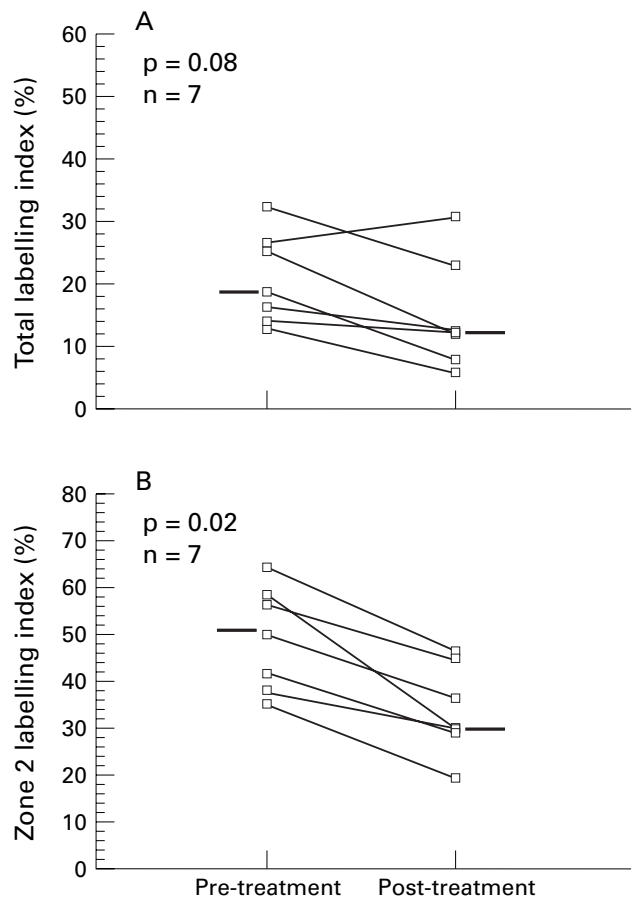

Figure 2 Total and zone 2 labelling indices in corpus before and after $H$ pylori eradication.

suitable for counting. Eradication of $H$ pylori resulted in a significant reduction in total and zone $2 \mathrm{LI} \%$ in the antrum/anastomosis and corpus biopsies.

CELL PROLIFERATION AND DIETARY SALT

There was no correlation between cell proliferation (total $\mathrm{LI} \%$ ) in antrum/anastomosis (17 patients) or corpus (16 patients) and urinary sodium to creatinine ratio $(r=-0.3 ; \mathrm{p}=0.24$; and $r=-0.1 ; \mathrm{p}=0.62$, respectively).
Table 3 Eradication of $H$ pylori from the

antrum/anastomosis and corpus of the gastric remnant leading to a reduction in total and zone 2 labelling indices

Remnant site

LI\%/treatment

group

Pre-eradication

Post-eradication

Antrum/anastomosis $(\mathrm{n}=10)$

Total LI\% $\quad 35.6(13.7$ to 51.4$) \quad 21.8(11.1$ to 55.2$)$ a

Zone $2 \mathrm{LI} \% \quad 64.8$ (47.6 to 83.4 ) $\quad 47.3$ (28.1 to 79.6 )b

Corpus $(\mathrm{n}=7)$

Total LI\% $\quad 18.8(13.1$ to 32.5$) \quad 12.8(6.2$ to 31.2$) \mathrm{c}$

Zone $2 \mathrm{LI} \% \quad 51.1$ (36.1 to 65.8$) \quad 31.4(20.3$ to 48.6$) \mathrm{d}$

Values are median (range)

a, $p=0.01 ; b, p=0.002 ; c, p=0.08 ; d, p=0.02$.

\section{Discussion}

The risk of gastric cancer developing in patients with peptic ulcer disease is lower than expected. ${ }^{22} 23$ However, following surgery for benign gastroduodenal disease there is an increased likelihood of developing gastric carcinoma. ${ }^{1-424}$ Animal studies have shown that after gastric surgery, duodenogastric reflux and denervation play an important role in the pathogenesis of cancer of the remnant. ${ }^{25} 26$ The risk of developing cancer is related to the degree of duodenogastric reflux in both the intact and post-surgical stomach without the administration of exogenous carcinogens. ${ }^{27} 28$

The normal mucosal response to damage is inflammation and regeneration, in which increased cell proliferation plays an important role. A persistent increase in cell proliferation and the presence of carcinogens are both thought to be of importance in carcinogenesis. ${ }^{13} 2930$ Increased labelling indices are present in gastric mucosal foveolae adjacent to gastrojejunostomy compared with mucosa near a gastrostomy, indicating that surgically induced reflux of duodenogastric contents increases mucosal proliferation. ${ }^{31}$ Studies of mucosal proliferation in the gastric remnant after partial gastrectomy show an upward shift of the proliferative compartment at the anastomosis ${ }^{32}$ compared with other areas of the gastric stump, ${ }^{33}$ while surgical diversion of bile leads to a reduction in gastric remnant epithelial proliferation. ${ }^{34} 35$

In this study we used MIB-1 as a marker of gastric epithelial proliferation. This immunohistochemical technique stains in an identical manner to the Ki67 antigen, ${ }^{36}$ which it represents, and correlates well with in vitro bromodeoxyuridine labelling in gastric ${ }^{37}$ and other tissue. ${ }^{38}$ We employed a modified Giemsa stain to detect $H$ pylori. It could be argued that a more sensitive technique for detecting $H$ pylori, namely immunohistochemical staining, should have been used. However, detection of $H$ pylori using the modified Giemsa stain has a very high sensitivity and specificity (98.8\% and $99.2 \%$, respectively), and in a large comparative study has been shown to be equivalent to the gold standard carbon-13 urea breath test (sensitivity $98.7 \%$ and specificity $98.4 \%) .{ }^{39}$ Given these figures, the false negative rate using the modified Giemsa stain is approximately $1 \%$ and would not, therefore, significantly affect the results of this study. 
We found no difference in gastric remnant epithelial proliferation between subjects with $H$ pylori infection and those subjects where the organism was absent. This finding contrasts with the results from previous work we have undertaken on gastric epithelial kinetics in the post-surgical stomach. ${ }^{20}$ The reason for the differing results is found in the types of gastric surgery present in patients who took part in the different studies. In our original study the $H$ pylori positive and negative groups were comparable in the types of gastric surgery represented. In this study they are not. Ten of the $12 \mathrm{H}$ pylori positive subjects had had vagotomy and pyloroplasty, in contrast to the $H$ pylori negative group which comprised patients with gastric surgery where the pylorus had been removed or bypassed. These types of surgery are associated with a greater degree of bile reflux and associated proliferative mucosal response than vagotomy and pyloroplasty surgery. ${ }^{34} \mathrm{H}$ pylori infection of the post-surgical stomach is found commonly in subjects with vagotomy and pyloroplasty, while bile reflux is strongly associated with Billroth I, Billroth II, and gastroenterostomy operations. ${ }^{40}{ }^{41}$ Bile acids inhibit the adherence of $\mathrm{H}$ pylori in vitro ${ }^{42}$ but the two can coexist. ${ }^{7}$ The greater degree of bile reflux in the $H$ pylori negative group may cause epithelial hyperproliferation comparable to that found in $H$ pylori infected subjects after vagotomy and pyloroplasty, where bile reflux is less marked.

The finding that cell proliferation is greater in the antrum/anastomosis than in the more proximal remnant is in keeping with the distal portion of the remnant being in greater contact with enterogastric reflux contents. The increased exposure to bile results in more gastric mucosal damage and therefore greater inflammatory and proliferative responses. In the $H$ pylori positive subjects the combination of the organism and bile reflux has been shown to have a synergistic effect on cell proliferation in the post-surgical stomach. ${ }^{20}$ The observation that in $H$ pylori negative subjects there is no difference in zone 2 cell proliferation between the distal and proximal gastric remnant is interesting. Damage to gastric mucosa by bile leads to a characteristic histological appearance, with foveolar hyperplasia. ${ }^{43}$ This may result in an upward expansion of the proliferative compartment to involve zone 1 . In this way the total proliferation of the gastric glands may be increased in the distal remnant in response to a greater degree of exposure to bile, but this effect is not seen in zone 2 because of the shift in the proliferative compartment. Little is known about epithelial kinetics in reflux gastritis affecting the intact stomach.

We used standard bismuth based triple therapy as our antihelicobacter regime. In previous work using this regime, the eradication rate was approximately $50 \% .{ }^{14}{ }^{17} \mathrm{By}$ using this treatment we had hoped to acquire an equal number of $H$ pylori positive and negative subjects post-treatment for the purpose of comparison. However, the treatment success rate was higher than expected.
Because we used the bismuth based triple therapy, follow up endoscopy and biopsy was delayed for at least three months. Bismuth is known to have an anti-inflammatory effect and may persist in the gastric mucosa for weeks. ${ }^{44}$ The delay in clearing bismuth has been highlighted by previous studies on gastric epithelial kinetics, ${ }^{14}{ }^{18}$ leading to a reduction in gastric mucosal cell proliferation whether the organism has been eradicated or not.

We have shown that eradication of $H$ pylori from the post-surgical stomach reduces epithelial proliferation. Though the study group comprised a heterogeneous collection of different types of gastric surgery, bile reflux is probably a common denominator for these patients. The effect of bile reflux was not specifically addressed in this study. Accurate measurement of bile reflux is technically difficult. ${ }^{45}$ One measurement of gastric bile acid concentration does not reflect the extent or duration of enterogastric reflux. ${ }^{46}$ In order to address this, the patients in the treatment group acted as their own controls. However, it is possible that eradication of $H$ pylori from the post-surgical stomach may in some way alter the degree of bile reflux and influence the labelling indices.

Previous studies on the effect of $\mathrm{H}$ pylori eradication on gastric mucosal cell proliferation have concentrated on the intact stomach. ${ }^{141747}$ The role of bile reflux on gastric remnant epithelial kinetics has also been studied. ${ }^{33} 34$ Bile and $H$ pylori appear to have a synergistic effect on gastric stump epithelial kinetics. ${ }^{20}$ This is the first report of the effect of $H$ pylori eradication on cell proliferation in the post-surgical stomach and provides evidence for the possible role of $H$ pylori as a promoter for gastric remnant carcinogenesis. It is possible that a subgroup of patients who have undergone gastric surgery for benign disease and are thereby exposed to duodenogastric reflux, and who also have persistent $H$ pylori infection, are at increased risk of developing gastric carcinoma of the remnant. Gastric stump epithelial proliferation may increase in response to $H$ pylori infection in a similar manner to the intact stomach, namely through compensatory hyperproliferation following cell damage, through the mucosal inflammatory response, ${ }^{47}{ }^{48}$ and through a direct effect by the organism on the epithelial cells. ${ }^{49}$

The dietary factor most consistently associated with gastric cancer is a high salt intake. ${ }^{8}$ Concentrated salt solution damages gastric mucosa, leading to inflammatory reparative changes, and is associated with mucosal atrophy. This damage increases cell proliferation which may amplify the action of carcinogens, ${ }^{50}$ perhaps by increasing the mutagenicity of nitrosated food. ${ }^{51}$ Increased cell proliferation and tumorigenesis occurs in rats fed a high salt diet after one dose of a N-nitroso compound. ${ }^{52}$ Given the importance of salt ingestion in the pathogenesis of gastric cancer we have sought to determine whether there is any relation between dietary salt intake and the degree of epithelial proliferation in the gastric remnant. We did not find any such correlation. This may have reflected the small sample size 
studied. Alternatively, the immunostaining technique used may not be sensitive enough to accurately reflect the mucosal state of proliferation. This explanation is unlikely. MIB-1 labelling in gastric mucosa correlates well with bromo-deoxyuridine immunostaining. ${ }^{37}$ Dietary salt has been shown to correlate with epithelial cell proliferation in $H$ pylori gastritis of the intact stomach. ${ }^{19}$ However, in this study PCNA was used as a marker of epithelial proliferation. Concerns have been expressed about the accuracy of this technique in gastric biopsy material ${ }^{37}$ It is possible that other factors, such as bile and $H$ pylori, have a greater effect on gastric remnant epithelial kinetics.

In conclusion dietary salt does not appear to affect cell proliferation in the post-surgical stomach. $H$ pylori increases cell proliferation in the gastric remnant and may play a role as a promoter of gastric stump carcinoma.

1 Offerhaus GJA, Tersmette AC, Huibregste $\mathrm{K}$, et al. Mortality caused by stomach cancer after remote partial gastrectomy for benign conditions; 40 years of follow-up of an Amsterdam cohort of 2633 postgastrectomy patients. Gut 1988;29:1588-90.

2 Caygill CPJ, Hill MJ, Kirkham JS, et al. Mortality from gastric cancer following gastric surgery for peptic ulcer. Lancet 1986;ii:502-5.

3 Clark CG, Ward MWN, McDonald AM, et al. The incidence of gastric stump cancer. World F Surg 1983;7: 236-40.

4 Northfield TC, Hall CN. Carcinoma of the gastric stump: risks and pathogenesis. Gut 1990;31:1217-19.

5 Sano C, Kumashiro R, Saito T, et al. Promoting effect of partial gastrectomy on carcinogenesis in the remnant stomN-nitrosoguanidine. Oncology 1984;41:124-8.

6 Weiman TJ, Max JH, Vogles CR, et al. Diversion of duodenal contents. Its effect on the production of experimental gastric cancer. Arch Surg 1980;115:959-61.

7 Sobala GM, O'Connor HJ, Axon ATR, et al. Histological consequences of bile reflux on the gastric mucosa, with special reference to intestinal metaplasia. 7 Clin Patho 1993;46:235-40

8 Chen J, Campbell TC, Peto R. Diet, life-style and mortality in China. A study of the characteristics of 65 Chinese counties. Oxford: Oxford University Press, 1990

9 Nomura A, Stemmermann GN, Chyou P, et al. H pylori infection and gastric carcinoma among Japanese Americans in Hawaii. N Engl f Med 1991;325:1132-6.

10 Forman D, Newell DG, Fullerton F, et al. Association between infection with Helicobacter pylori and risk of gastric cancer: evidence from a prospective investigation. BMF tric cancer: eviden

11 Parsonnet J, Friedman GD, Vandersteen DP, et al. Helicobacter pylori infection and the risk of gastric carcinoma. N Engl f Med 1991:325:1172-31.

12 The Eurogast Study Group. An international association between Helicobacter pylori infection and gastric cancer. Lancet 1993;341:1359-62.

13 Medline A, Farber E. The multi-step theory of neoplasia. In Anthony PP, Sweeney RMN, eds. Recent advances in histopathology, No 11. Edinburgh: Churchill Livingstone, 1981:19-34.

14 Lynch DAF, Mapstone NP, Clarke AMT, et al. Cell proliferation in Helicobacter pylori associated gastritis and the effect of eradication therapy. Gut 1995;36:346-50.

15 Brenes F, Ruiz B, Correa P, et al. Helicobacter pylori causes hyperproliferation of the gastric epithelium: pre- and posteradication indices of proliferating cell nuclear antigen. $\mathrm{Am}$ eradication indices of proliferating

16 Cahill RJ, Sant S, Beattie S, et al. Helicobacter pylori and increased cell proliferation: a risk factor for gastric cancer. Eur $\mathcal{f}$ Gastroenterol Hepatol 1994;6:43-5

17 Cahill RJ, Xia H, Kilgallen C, et al. Effect of Helicobacter pylori eradication on gastric epithelial proliferation. Dig Dis Sci 1995;40:1627-31

18 Fraser AG, Sim R, Sankey EA, et al. Effect of eradication of Helicobacter pylori on gastric epithelial cell proliferation. Aliment Pharmacol Ther 1994;8:167-73.

19 De-Koster E, Buset M, Fernandes E, et al. Helicobacter pylori: the link with gastric cancer. Eur f Cancer Prev 1994 3:247-57.

20 Lynch DAF, Mapstone NP, Clarke AMT, et al. Cell proliferation in the gastric corpus in Helicobacter pylori associated gastritis and after gastric resection. Gut 1995;36: 351-3.

21 Correa P, Montes G, Cuello C, et al. Urinary sodium-tocreatinine ratio as an indicator of gastric cancer risk. Nat Cancer Inst Monogr 1985;69:121-3.

22 Hole DJ, Quigley EMM, Gillis ER, et al. An examination of the relationship between chronic peptic ulcer and gastric carcinoma. Scand $\mathcal{F}$ Gastroenterol 1987;22:17.
23 Lee A, Fox J, Hazell S. Pathogenicity of Helicobacter pylori: a perspective. Infect Immun 1993;61:1601-10.

24 Caygill CP, Knowles RL, Hall R. Increased risk of cancer mortality after vagotomy for peptic ulcer: a preliminary analysis. Eur f Cancer Prev 1991;1:35-7.

25 Stael Von Holstein C, Willen R, Eriksson S. Gastric stump carcinoma in rats-a reliable gastric cancer model. In Vivo 1990;4:65-9.

26 Kaminishi M, Shimizu N, Shiomoyama S, et al. Etiology of gastric remnant cancer with special reference to the effects of denervation of the gastric mucosa. Cancer (suppl) 1995; 75:1490-6.

27 Langhans P, Heger R, Hohenstein J, et al. Operation sequel carcinoma of the stomach. Experimental studies of surgical techniques with and without resection. World f Surg 1981; 5:595-605.

28 Miwa K, Hattori T, Miyazaki I. Duodenogastric reflux and foregut carcinogenesis. Cancer (suppl) 1995;6:1426-32.

29 Biasco G, Paganelli GM, Santucci R, et al. Cell proliferation kinetics as a marker of gastric cancer risk. Ital $\mathcal{f}$ Gastroenterol 1991;23:24-8.

30 Cahill RJ, Kilgallen C, Beattie S, et al. Gastric epithelial kinetics in the progression from normal mucosa to gastric carcinoma. Gut 1996;38:177-81.

31 Taylor PR, Mason RC, Filipe MI, et al. Gastric carcinogenesis in the rat induced by duodenogastric reflux without carcinogens: morphology, mucin histochemistry, polyamine metabolism, and labelling index. Gut 1991;32: 1447-54.

32 Offerhaus GJ, van de Stadt J, Samson G, et al. Cell proliferation kinetics in the gastric remnant. Eur $\mathcal{F}$ Cancer Clin Oncol 1985;21:73-9.

33 Ohyama S, Yonemura Y, Miwa K, et al. Proliferation assay of human gastric remnant by bromodeoxyuridine and flow cytometry. Gastroenterology 1992;103:789-93.

34 Bechi P, Balzi M, Becciolini A, et al. Gastric cell proliferation kinetics and bile reflux after partial gastrectomy. Am f Gastroenterol 1991;86:1424-32.

35 Imai T, Kobayasi S, Rodrigues MA, et al. Reduction of cell proliferative activities of gastric stump adenomatous hyperplasias after bile reflux diversion in rats. Carcinogenesis 1993;14:1765-9.

36 Key G, Becker MH, Baron B, et al. New Ki-67-equivalent murine monoclonal antibodies (MIB 1-3) generated gainst bacterially expressed parts of the Ki-67 cDNA containing three 63 base pair repetitive elements encoding for the Ki-67 epitope. Lab Invest 1993;68:629-36.

37 Lynch DAF, Clarke AMT, Jackson P, et al. Comparison of labelling by bromodeoxyuridine, MIB-1, and proliferating cell nuclear antigen in gastric mucosal specimens. F Clin Pathol 1994;47:122-5.

38 Onda K, Davis RL, Shibuya M, et al. Correlation between the bromodeoxyuridine labelling index and the MIB-1 and Ki67 proliferating cell indices of cerebral gliomas. Cancer 1994;74:1921-6.

39 Moayyedi P, Dixon MF. Any role left for invasive tests? Histology in clinical practice. Gut 1998;43(suppl 1):S51-5.

40 O'Connor HJ, Axon ATR. Campylobacter pylori, gastric ulceration and the post-operative stomach. In: Rathbone BJ, Heatley RV, eds. Campylobacter pylori in gastroduodenal disease. Oxford: Blackwell Scientific Publications, 1989: $125-38$.

41 Offerhaus GJ, Rieu PN, Jansen JB, et al. Prospective comparative study of the influence of post-operative bile reflux on gastric mucosal histology and Campylobacter pylori. Gut 1989;30:1552-7.

42 Mathai E, Arora A, Cafferkey M, et al. The effect of bile acids on the growth and adherence of Helicobacter pylori. Aliment Pharmacol Ther 1991;5:653-8.

43 Dixon MF, O'Connor HJ, Axon ATR, et al. Reflux gastritis: distinct histopathological entity? f Clin Pathol 1986;39: 524-30.

44 Lanza FL, Skoglund ML, Rack MK, et al. The effect of bismuth subsalicylate on the histologic gastritis seen with Campylobacter pylori: a placebo-controlled, randomized study. Am $\mathcal{f}$ Gastroenterol 1991;86:16-25.

45 Hofmann AF. The enterohepatic circulation of bile acids in health and disease. In: Sleisenger $\mathrm{MH}$, Fordtran JS, eds. Gastrointestinal disease, vol 1, 5th ed. Philadelphia: WB Saunders, 1993:127-50.

46 Houghton PWJ, Mortensen NJ, Thomas WEG, et al. Intragastric bile acids and scintigraphy in the assessment of duodenogastric reflux. Br $\mathcal{F}$ Surg 1986;73:292-4.

47 Lynch DAF, Mapstone NP, Lewis F, et al. Correlation between cell proliferation in $\mathrm{H}$ pylori associated gastritis and histological scoring using the Sidney system. Gut 1993(suppl);34:F197.

48 Emery P, Salmon M. Systemic mediators of inflammation. Br f Hosp Med 1991;45:164-8.

49 Fan XG, Kelleher D, Fan XJ, et al. Helicobacter pylori increases proliferation of gastric epithelial cells. Gut 1996;38:167-73

50 Ames BN, Gold LS. Too many rodent carcinogens: mitogenesis increases mutagenesis. Science 1990;24:970-1.

51 Rogas-Campos N, Sigaran N, Bravo AC, et al. Salt enhances the mutagenicity of nitrosated black beans. Nutr Cancer 1990;14:1-3.

52 Watanabe $\mathrm{H}$, Takahashi $\mathrm{T}$, Okamoto $\mathrm{T}$, et al. Effects of sodium chloride and ethanol on stomach tumorigenesis in ACI rats treated with N-methyl-N-nitro-Nnitrosoguanidine: a quantitative approach. Fpn f Cancer Res 